\title{
Points to Ponder: Protective gear for Sri Lankan Motorcyclist \\ Paranitharan $\mathbf{P}$ \\ Department of Forensic Medicine, Faculty of Medicine, University of Kelaniya
}

Email:paran28@gmail.com

(iD) https://orcid.org/0000-0002-1913-6085

Injuries on motorcycle riders admitted after collisions range from minor abrasions to fractures and other major injuries to different regions of the body. ${ }^{1}$

The motorcyclists who are involved are employed at different institutions. It is imperative that they report back to duty following hospital treatment.

Cushioning of major impacts to the body following a collision will minimize the injuries and reduce hospital stay. Further the expenses spent on treating major injuries by the government could be minimized. ${ }^{2}$

Currently it is illegal to ride a motorcycle without a helmet. The suggested protective gear which is used in other countries can be encouraged in Sri Lanka too.

The sport of cricket was played with minimal protection in the past. However, after experiencing several injuries the sport is played with maximum protection to the body.

A suggestion is proposed to encourage Sri Lankan motorcyclists to use additional protective gear to minimize injuries to different parts of the body. (Figure 1)

Keywords; injuries, motorcyclist, protective gear

All articles in Sri Lanka Journal of Forensic Medicine, Science \& Law are licensed under the terms of the Creative Commons Attribution-Non Commercial 4.0 International License 


\section{Protective gear for a Sri Lankan motorcyclist}

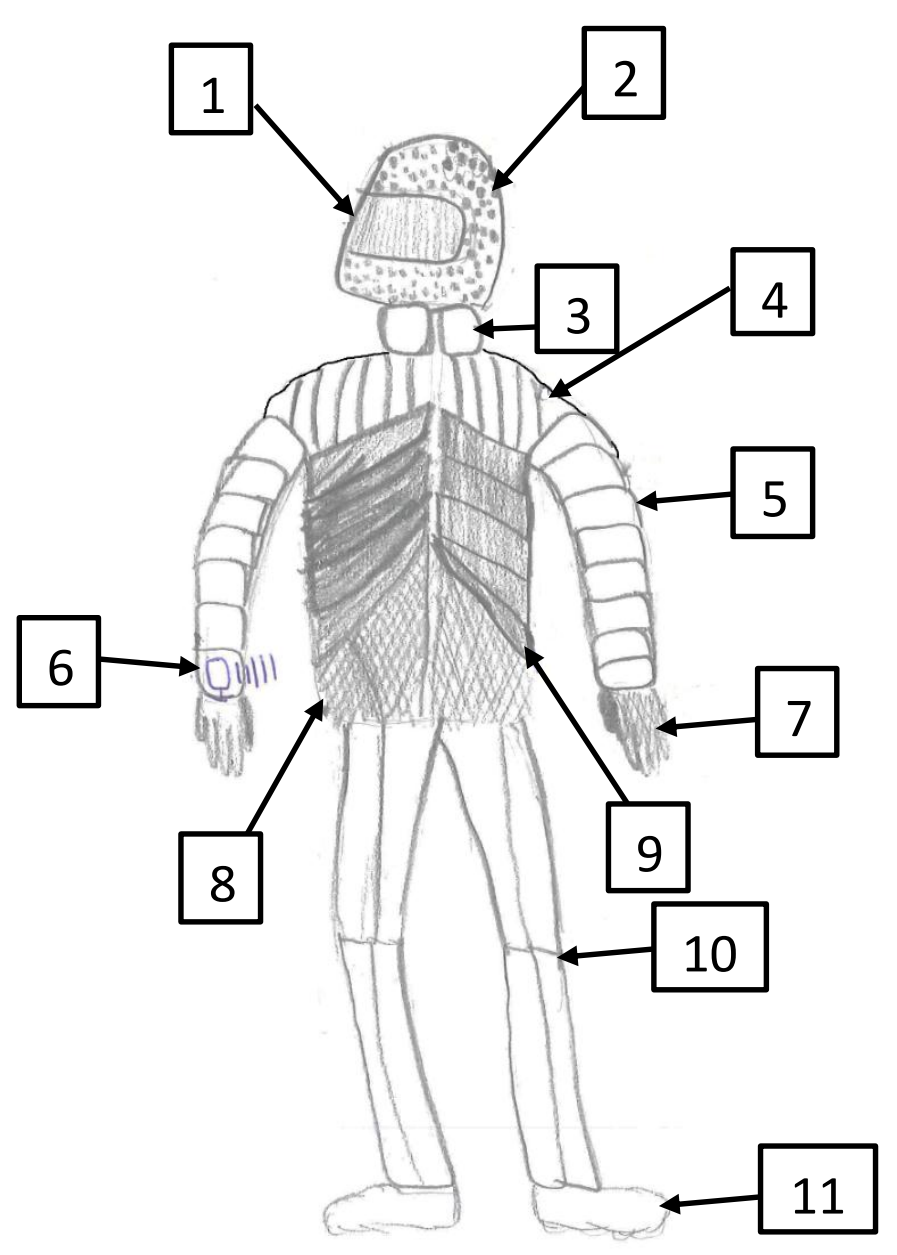

1. Shockproof visor

2. Rubber padded helmet

3. Thickly padded high neck collar

4. Strong rubber lines to guard areas of collar bone

5. Cuff like padded long sleeves

6. Speed sensors that vibrate when the speed limit is exceeded

7. Cross fiber glove

8. Cross fiber jacket to prevent exposed areas being injured

9. Thickly padded lower portion to prevent ribcage fractures

10. Thickly padded trousers (Exoskeleton)

11. Rubber studded shoes with padding inside

Figure 1

\section{References}

1. Abeysekera WYM, Gamage RT,De Almeida M. Motor bicycle and three wheeler related road traffic accidents - burden to accident and emergency service of a tertiary care hospital: a clinical audit. The Sri Lanka Journal of Surgery. 2015; 33(4): 20-22. DOI: $10.4038 /$ sljs.v33i4.8200
2. Lizde R, Rebecca L, Michael F, Wei Du, Narelle H, Stephane H, Drew R. Motorcycle protective clothing: Protection from injury or just the weather?. Accident Analysis \& Prevention. 2011; 43(6): 1893-19. DOI: 10.1016/j.aap.2011.04.027 